Bond University

Research Repository

\title{
Drinking motives, alcohol expectancies and alexithymia in young adult social drinkers
}

\author{
Lyvers, Michael; Simons, Olivia; Hayes, Amelia; Thorberg, Fred Arne
}

\section{Published in:}

Journal of Substance Use

DOI:

10.3109/14659891.2012.734538

\section{Licence:}

CC BY-NC-ND

Link to output in Bond University research repository.

Recommended citation(APA):

Lyvers, M., Simons, O., Hayes, A., \& Thorberg, F. A. (2014). Drinking motives, alcohol expectancies and alexithymia in young adult social drinkers. Journal of Substance Use, 19(1-2), 44-47.

https://doi.org/10.3109/14659891.2012.734538

\footnotetext{
General rights

Copyright and moral rights for the publications made accessible in the public portal are retained by the authors and/or other copyright owners and it is a condition of accessing publications that users recognise and abide by the legal requirements associated with these rights.
}

For more information, or if you believe that this document breaches copyright, please contact the Bond University research repository coordinator. 
Drinking Motives, Alcohol Expectancies and Alexithymia in Young Adult Social Drinkers Michael Lyvers, Ph.D.

Olivia Simons, Postgraduate Diploma of Psychology

Amelia Hayes, Postgraduate Diploma of Psychology

Department of Psychology

Bond University

Gold Coast Qld 4229 Australia

Fred Arne Thorberg, Ph.D.

Department of Behavioral Sciences in Medicine

Institute of Basic Medical Sciences

Faculty of Medicine, University of Oslo

Oslo, Norway

This is an Accepted Manuscript version of the following article:

Lyvers, M., Simons, O., Hayes, A., \& Thorberg, F. A. (2014). Drinking motives, alcohol expectancies and alexithymia in young adult social drinkers. Journal of Substance Use, 19(1-2), 44-47. https://doi.org/10.3109/14659891.2012.734538.

It is deposited under the terms of the Creative Commons Attribution-NonCommercial-NoDerivatives License, which permits non-commercial re-use, distribution, and reproduction in any medium, provided the original work is properly cited, and is not altered, transformed, or built upon in any way. 


\begin{abstract}
The present study examined alexithymia, drinking motives and alcohol expectancies in a nonclinical sample of 100 young adults aged 18-30 years. Those with alexithymia scored higher on measures of coping motives for drinking and affective change expectancies than those without alexithymia. The findings suggest that people with alexithymia are more likely to drink to cope, but also to experience feelings of intensified negative mood after drinking, compared to people without alexithymia even when both groups show similar levels of drinking.
\end{abstract}

KEYWORDS: alcohol, alexithymia, drinking motives, alcohol expectancies drinkers. Journal of Substance Use, 19(1-2), 44-47. https://doi.org/10.3109/14659891.2012.734538. 
Alexithymia refers to difficulties identifying and describing feelings and an externally oriented thinking style (Nemiah, Freyberger \& Sifneos, 1976). Alexithymic individuals tend to confuse somatic sensations with emotional feelings and have an elevated risk of alcohol problems. Between 45-67\% of patients undergoing treatment for alcohol dependence exhibit alexithymia (Thorberg, Young, Sullivan, \& Lyvers, 2009), compared to only 5-13\% of the general population (Kokkonen, Karvonen, Veijola, Laksy \& Jokelainen, 2001; Mattila et al., 2007). The anxiolytic and disinhibiting effects of alcohol may reduce high levels of stress and enable alexithymic individuals to overcome their inability to experience or express emotion (Finn, Martin, \& Phil, 1987). Consistent with this idea, Thorberg et al. (2011ab) found that the relationship between alexithymia and alcohol dependence was partially mediated by alcohol expectancies of affective change and assertion. Moreover, alexithymics reported higher levels of both expectancies compared to non-alexithymics. Thus those with alcohol dependence and alexithymia may drink in order to experience or release negative emotions as well as be more socially expressive. Perhaps for such functional reasons, maintaining abstinence appears to be more difficult for alcohol dependent patients presenting with alexithymia (Loas, Fremaux, Otmani, Lecercle \& Delahousse, 1997).

Drinking motives influence drinking through the anticipation of certain drinking outcomes (Cooper, 1994; O’Brien, Hunter, Kypri, \& Ali, 2008) and are more proximal to drinking behavior than alcohol expectancies (Hasking, Lyvers \& Carlopio, 2011; Lyvers, Hasking, Hani, Rhodes \& Trew, 2010). Social motives for drinking reflect anticipation of social facilitation by alcohol (Stewart \& Chambers, 2000), whereas enhancement motives refer to anticipation of alcohol-enhanced mood (Neighbors et al., 2004). Social and enhancement motives thus involve seeking positive reinforcement from drinking via external or internal rewards, respectively - motives that are widely endorsed by young adult social

This is an Accepted Manuscript version of the following article:

Lyvers, M., Simons, O., Hayes, A., \& Thorberg, F. A. (2014). Drinking motives, alcohol expectancies and alexithymia in young adult social drinkers. Journal of Substance Use, 19(1-2), 44-47. https://doi.org/10.3109/14659891.2012.734538. 
drinkers (Kuntsche et al., 2006). By contrast, coping motives reflect anticipated negative reinforcement via suppression of negative affect, an avoidance strategy that entails a high risk of future alcohol dependence and alcohol-related problems (Feil \& Hasking, 2008; Gire, 2002). A recent study (Lyvers, Hasking, Albrecht \& Thorberg, 2012) of 262 adults aged 2057 years found that those with alexithymia reported stronger coping motives and higher sensitivity to punishment compared to those with borderline or no alexithymia, and that the relationship between sensitivity to punishment and drinking was mediated by coping motives. These results suggested that alcohol is used by individuals with alexithymia to cope with negative affect.

In Australia, young adults aged 18-30 show the highest level of alcohol consumption of any comparable age group (AIHW, 2008). Evidence suggests that risky drinking by young adults more strongly reflects external influences rather than internal factors such as coping needs or alexithymia (Casswell et al., 2002; Read, Wood, Kahler, Maddock \& Palfai, 2003). Nevertheless, alexithymia is frequently associated with anxiety and stress (DeGucht et al., 2004; de Timary et al., 2008), and the tendency to drink to alleviate such feelings entails an increased risk of alcohol problems later in life (Schmidt, Buckner \& Keough, 2007). The present study examined drinking motives and alcohol expectancies in concert to explore whether these drinking constructs characterize young adult social drinkers with alexithymia, possibly increasing their risk for future alcohol problems.

\section{Method}

\section{$\underline{\text { Participants }}$}

Participants were recruited through the undergraduate psychology participant pool and via advertisements in a local community newspaper. Of the initial 137 who volunteered for this study, 100 young adults ( 28 men, 72 women) met the criteria for participation (social 
drinkers aged 18-30 years with no history of diagnosed psychological, neurological or substance use disorder) and provided usable data. The age range was $18-30(M=21.00$ years, $S D=2.70$ ), and 69 were current students. Undergraduate psychology students were offered 1 credit point for their participation. Community participants were recruited through an advertisement placed in the classified section of the Gold Coast Bulletin and were paid \$20 for their participation.

$\underline{\text { Materials }}$

All participants completed a self-report survey consisting of the following measures, which were administered on a university computer via the online survey website Survey Monkey.

Demographic Questionnaire. This brief questionnaire included questions concerning the participants' age, gender, student status, highest level of education, and drinking status.

Toronto Alexithymia Scale (TAS-20). The TAS-20 is a 20 -item self-report scale developed by Bagby, Parker and Taylor (1994) to measure alexithymia. Reponses are recorded on a 5-point Likert scale with higher scores indicating higher levels of alexithymia. The sum of scores on each item constitutes the total scale score with some items being reverse scored. Cut-off scores have been established such that total scores of 61 or higher indicate alexithymia, scores between 52 and 60 reflect borderline alexithymia, and scores of 51 or less indicate no alexithymia.

Alcohol Use Disorders Identification Test (AUDIT). Developed by Saunders, Aasland, Babor, de la Fuente and Grant (1993), the AUDIT is a widely used 10-item selfreport measure used to identify domains of alcohol use. Items 1-8 are measured on a 5-point Likert scale whereas items 9 and 10 are measured on a 3-point scale. Item scores are summed to obtain a total score. Scores between 0-7 are indicative of low risk drinking, 8-15 suggest

This is an Accepted Manuscript version of the following article:

Lyvers, M., Simons, O., Hayes, A., \& Thorberg, F. A. (2014). Drinking motives, alcohol expectancies and alexithymia in young adult social drinkers. Journal of Substance Use, 19(1-2), 44-47. https://doi.org/10.3109/14659891.2012.734538. 
hazardous drinking, 16-19 signify harmful drinking and scores of 20 or higher indicate dependent drinking.

Drinking Expectancies Questionnaire (DEQ). The DEQ was developed to assess beliefs concerning the effects of alcohol (Young \& Oei, 1996). The full scale contains 43 items, each measured on a 5-point Likert scale, with some items reverse-scored. Sums of items on the corresponding subscales provide scores on each of six alcohol expectancies. For the purposes of the present study only the following three subscales were used: Assertion, e.g., "Drinking makes me feel outgoing and friendly"; Affective Change, e.g., "Drinking makes me bad tempered"; and Tension Reduction, e.g., "I do not drink alcohol to help me unwind after a hard day or week's work."

Drinking Motives Questionnaire (DMQ). This 20-item measure was originally developed by Cooper, Russell, Skinner and Windle (1992) to evaluate motivations to consume alcohol. Items are measured on a 6-point Likert scale in response to the stem "How often do you drink..." and tap into three domains of drinking motives: Enhancement, e.g., "because you like the feeling"; Coping, e.g., "to forget your worries"; and Social, e.g., "to celebrate a special occasion with friends." Scores for each motive are obtained by summation of scores for the corresponding subscale, with higher scores indicating stronger endorsement of that motive.

\section{Procedure}

Approval was granted for this study by the Bond University Human Research Ethics Committee prior to data collection. Undergraduate psychology students were recruited via an explanatory statement placed on the Psychology Notice Board. Interested students provided contact details and were subsequently contacted via email, phone or text message to arrange a time and place at Bond University to complete the online survey on a university computer.

This is an Accepted Manuscript version of the following article:

Lyvers, M., Simons, O., Hayes, A., \& Thorberg, F. A. (2014). Drinking motives, alcohol expectancies and alexithymia in young adult social drinkers. Journal of Substance Use, 19(1-2), 44-47. https://doi.org/10.3109/14659891.2012.734538. 
Participants were told of their right to withdraw from the study at any time without penalty and that all responses were anonymous. Upon completion students were issued with a credit slip and thanked for their time.

Community members were recruited through a local newspaper advertisement. Those interested contacted a researcher and arrangements were made for an appropriate time to complete the online survey on a Bond University computer. Again, participants were told of their right to withdraw from the study at any time without penalty and that all responses were anonymous. Upon completion the community members were individually paid \$20 in cash and thanked for their time.

\section{Results}

Chi-square test showed that student and community subsamples differed in gender composition, $\chi^{2}(1)=4.40, p=.04$. Of the community subsample $44 \%$ were men compared to only $24 \%$ of the psychology student subsample, reflecting the typically higher proportion of female as opposed to male psychology undergraduates. Multivariate analysis of covariance (MANCOVA) comparing student and community subsamples on all dependent measures while controlling for gender showed no significant effect of subsample. Further there was not a significant association between TAS-20-defined alexithymia group (alexithymic, borderline alexithymic, non-alexithymic) and gender in this sample, $\chi^{2}(2)=4.49, p=.11$.

Intercorrelations were calculated among all variables and the results are shown in Table 1. The important correlations to note in Table 1 include the predicted significant positive correlations of TAS-20 scores with DMQ Coping motives for drinking and DEQ Affective Change and Assertion expectancies, and the significant positive correlations among AUDIT, DMQ drinking motives and DEQ drinking expectancies.

This is an Accepted Manuscript version of the following article:

Lyvers, M., Simons, O., Hayes, A., \& Thorberg, F. A. (2014). Drinking motives, alcohol expectancies and alexithymia in young adult social drinkers. Journal of Substance Use, 19(1-2), 44-47. https://doi.org/10.3109/14659891.2012.734538. 
A multivariate analysis of covariance (MANCOVA) was conducted on AUDIT,

DMQ and DEQ measures for the three TAS-20-defined alexithymia groups (non-alexithymic, $n=54$; borderline alexithymic, $n=27$; alexithymic, $n=19$ ), with gender as the covariate.

Box's M Test was not significant $(p=.48)$ indicating no violation. The multivariate effect of alexithymia group was significant according to Pillai's Trace, $F(14,182)=2.45, p=.003, \eta 2$ $=.16$, observed power $=.98$. Univariate effects were significant for Coping motives, $F(2,96)$ $=3.60, p=.03, \eta 2=.07$, observed power $=.65$, and Affective Change expectancies, $F(2,96)$ $=4.70, p=.01, \eta 2=.09$, observed power $=.78$. According to Tukey post test, alexithymics scored significantly higher on Coping motives $(M=14.42, S D=6.40)$ than non-alexithymics $(M=11.02, S D=4.36), p=.03$; and alexithymics scored significantly higher on Affective Change expectancies $(M=25.79, S D=7.08)$ than non-alexithymics $(M=20.83, S D=6.15)$, $p=.01$

\section{Discussion}

The present findings in young Australian adults, a group characterized by high levels of risky drinking (AIHW, 2008), indicate that alexithymia was associated with stronger DMQ-Coping motives and DEQ-Affective Change expectancies compared to young adults without alexithymia, as predicted. In contrast to Thorberg et al. (2011b) the difference between alexithymics and non-alexithymics on DEQ-Assertion expectancies was not significant; however TAS-20 alexithymia score was significantly positively correlated with DEQ Assertion expectancies, providing partial support for such a relationship. Overall the findings suggest that alexithymia is associated with distinct drinking motives and expectancies in young adult social drinkers that may predispose those with alexithymia to later development of alcohol dependence or other alcohol-related problems.

This is an Accepted Manuscript version of the following article:

Lyvers, M., Simons, O., Hayes, A., \& Thorberg, F. A. (2014). Drinking motives, alcohol expectancies and alexithymia in young adult social drinkers. Journal of Substance Use, 19(1-2), 44-47. https://doi.org/10.3109/14659891.2012.734538. 
An intriguing aspect of the present findings is that the alcohol expectancy dimension of Affective Change is considered a negative alcohol outcome expectancy factor, assessing beliefs about negative changes in affect occurring as a result of alcohol use. These negative expectancies are often believed to inhibit drinking (McMahon, Jones, \& O'Donnell, 1994). On the other hand, DMQ Coping motives assess drinking to suppress negative affect. One interpretation of this apparent contradiction is that alexithymic social drinkers more often use alcohol to cope with negative affect than do non-alexithymic social drinkers, but in addition the disinhibiting effects of alcohol may render alexithymic drinkers more open in their expression of emotions. Perhaps alcohol thus releases suppressed negative emotions such as anger more often than in those without alexithymia, promoting affective change expectancies in those with alexithymia. Future research is needed to replicate these findings in larger analogue samples.

As coping motives for drinking are associated with elevated risk of future alcohol dependence (Cooper, 1994; Feil \& Hasking, 2008; Gire, 2002; Schmidt et al., 2007), progression from social drinking to eventual alcohol dependence may not be an uncommon trajectory for young adults with alexithymia. Although alexithymic and non-alexithymic young adults showed no difference on the index of current alcohol consumption AUDIT in the present study, this was expected given the age range of the sample. The alcohol dependent patients in Thorberg et al.'s (2011b) study were considerably older than the young adult social drinkers in the present study, with a mean age of 39 years in Thorberg et al.'s alcohol dependent sample compared to only 21 years in the present social drinker sample. The progression to alcoholism in alexithymics is likely to be relatively late in onset, consistent with Type I alcoholism (Varma et al., 1994). Further, as discussed previously above, young Australian adults are characterized by high levels of risky drinking, which 
tends to be driven more by external than internal factors at that age (Casswell et al., 2002; Read et al., 2003). The very strong correlations of drinking level (as measured by AUDIT) with endorsement of social and enhancement motives for drinking in the present sample are highly consistent with that interpretation.

In conclusion, the present findings suggest that the personality trait of alexithymia is associated with specific drinking motives and beliefs about alcohol that may expose young adults with alexithymia to significant risk of excessive drinking and later alcohol use disorders or other alcohol-related problems. To verify this idea, longitudinal research is needed to delineate the developmental trajectory of alcohol use disorders in those with alexithymia. Patients undergoing treatment for alcohol problems who have alexithymia may benefit from a treatment approach that addresses their unique issues with emotional expression. 


\section{References}

Australian Institute of Health and Welfare (AIHW) (2008). 2007 National Drug Strategy

Household Survey. Canberra: Australian Government Publishing Service.

Bagby, R., Parker, J., \& Taylor, G. (1994). The twenty-item Toronto Alexithymia Scale-I. Item selection and cross-validation of the factor structure. Journal of Psychsomatic Research, 38(1), 23-32.

Cooper, M. (1994). Motivations for alcohol use among adolescents: Development and validation of a four-factor model. Psychological Assessment, 6(1), 117-128.

Cooper, M., Russell, M., Skinner, J., \& Windle, M. (1992). Development and validation of a three-dimensional measure of drinking motives. Psychological Assessment, 4, 123 132.

De Gucht, V., Fischler, B., \& Heiser, W. (2004a). Neuroticism, alexithymia, negative affect, and positive affect as determinants of medically unexplained symptoms. Personality and Individual Differences, 36(7), 1655-1667.

de Timary, P., Emmanuel, R., Luminet, O., Fillee, C., \& Mikolajczak, M. (2008).

Relationship between alexithymia, alexithymia factors and salivary cortisol in men exposed to a social stress test. Psychoneuroendocrinology, 33(8), 1160-1164.

Feil, J., \& Hasking, P. (2008). The relationship between personality, coping strategies and alcohol use. Addiction Research and Theory, 16(5), 526-537.

Finn, P., Martin, J., \& Pihl, R. (1987). Aleixthymia in males at high genetic risk for alcoholism. Psychotherapy and Psychosomatics, 47(1), 18-21.

Gire, J. (2002). A cross-national study of motives for drinking alcohol. Substance Use \& Misuse, 37(2), 215-223. 
Hasking, P., Lyvers, M., \& Carlopio, C. (2011). The relationship between coping strategies, alcohol expectancies, drinking motives and drinking behavior. Addictive Behaviors, $36(1), 479-487$.

Kokkonen, P., Karvonen, J.T., Veijola, J., Laksy, K., \& Jokelainen, J. (2001). Perceived and sociodemographic correlates of alexithymia in a population sample of young adults. Comprehensive Psychiatry, 42(6), 471-476.

Kuntsche, E., Knibbe, R., Gmel, G., \& Engels, R. (2006). Replication and validation of the Drinking Motive Questionnaire Revised (DMQ-R, Cooper, 1994) among adolescents in Switzerland. European Addiction Research, 12(3), 161-168.

Loas, G., Fremaux, D., Otmani, O., Lecercle, C., \& Delahousse, J. (1997). Is alexithymia a negative factor for mainaining abstinence? A follow-up study. Comprehensive Psychiatry, 38(5), 296-299.

Lyvers, M., Hasking, P., Albrecht, B., \& Thorberg, F.A. (2012). Alexithymia and alcohol: The roles of punishment sensitivity and drinking motives. Addiction Research \& Theory, in press.

Lyvers, M., Hasking, P., Hani, R., Rhodes, M., \& Trew, E. (2010). Drinking motives, drinking restraint and drinking behavior among young adults. Addictive Behaviors, $35,116-122$.

McMahon, J., Jones, B. T., \& O'Donnell, P. (1994). Comparing positive and negative alcohol expectancies in male and female social drinkers. Addiction Research, 1(4), 349-365. Mattila, A., Ahola, K., Honkonen, T., Salminen, J., Huhtala, H., \& Joukamaa, M. (2007). Alexithymia and occupational burnout are strongly associated in a working population. Journal of Psychometric Research, 62(1), 657-665. 
Neighbors, C., Larimer, M., Geisner, I., \& Knee, C. (2004). Feeling controlled and drinking motives among college students: Contingent self-esteem as a mediator. Self and Identity, 3(3), 207-224.

Nemiah, J.C., Freyberger, H., \& Sifneos, P.E. (1976). Alexithymia: A view of the psychosomatic process. In O. W. Hill (Ed.), Modern trends in psychosomatic medicine, vol. 3 (pp. 430-439). London: Butterworths.

O’Brien, K., Hunter, J., Kypri, K., \& Ali, A. (2008). Gender equality in university sportspeople's drinking. Drug and Alcohol Review, 27(6), 659-665.

Reinert, D., \& Allen, J. (2007). The Alcohol Use Disorders Identification Test: An update of research findings. Alcoholism: Clinical and Experimental Research, 31(2), 185-199.

Saunders, J., Aasland, O., Babor, T., de la Fuente, J.R., \& Grant, M. (1993). Development of the Alcohol Use Disorders Identification Test (AUDIT): WHO collaborative project on early detection of persons with harmful alcohol consumption-II. Addiction, 88(6), 791-804.

Stewart, S., \& Chambers, L. (2000). Relationships between drinking motives and drinking restraint. Addictive Behaviors, 25(2), 269-274.

Thorberg, F., Young, R., Sullivan, K., \& Lyvers, M. (2009). Alexithymia and alcohol use disorders: A critical review. Addictive Behaviors, 34, 237-245.

Thorberg, F., Young, R., Sullivan, K., Lyvers, M., Hurst, C., Connor, J., \& Feeney, G. (2011a). Alexithymia in alcohol dependent patients is partially mediated by alcohol expectancy. Drug and Alcohol Dependence, 116, 238-241.

Thorberg, F. A., Lyvers, M., Young, R. McD., Sullivan, K. A., Hurst, C., Connor, J. P., \& Feeney, GFX. (2011b). Alexithymia in relation to alcohol expectancies in a heavy drinkers. Journal of Substance Use, 19(1-2), 44-47. https://doi.org/10.3109/14659891.2012.734538. 
drinking population. Presented at the $164^{\text {th }}$ Annual Meeting of the American Psychiatric Association, Honolulu, Hawaii, USA, May 2011.

Varma, V. K., Basu, D., Malhotra, A., Sharma, A., \& Mattoo, S. K. (1994). Correlates of early- and late-onset alcohol dependence. Addictive Behaviors, 19, 609-619.

Young, R., Connor, J., Ricciardelli, L., \& Saunders, J. (2006). The role of alcohol expectancy and drinking refusal self-efficacy beliefs in university student drinking. Alcohol and Alcoholism, 41(1), 70-75.

Young, R., \& Oei, T. (1996). Drinking Expectancy Profile: Test Manual. Australia: Behavior Research and Therapy Center, University of Queensland. 
Table 1

Intercorrelations among study variables.

\begin{tabular}{|c|c|c|c|c|c|c|c|c|}
\hline & Age & TAS & AUDIT & $\begin{array}{c}\text { DMQ } \\
\text { Enhance }\end{array}$ & $\begin{array}{c}\text { DMQ } \\
\text { Coping }\end{array}$ & $\begin{array}{l}\text { DMQ } \\
\text { Social }\end{array}$ & $\begin{array}{c}\text { DEQ } \\
\text { Assertion }\end{array}$ & $\begin{array}{c}\text { DEQ } \\
\text { Affective } \\
\text { Change }\end{array}$ \\
\hline TAS & -.065 & & & & & & & \\
\hline AUDIT & -.035 & .154 & & & & & & \\
\hline Enhancement & -.057 & .073 & $.616^{* *}$ & & & & & \\
\hline Coping & -.037 & $.265^{* *}$ & $.376^{* *}$ & $.494 * *$ & & & & \\
\hline Social & $-.211 *$ & .036 & $.585^{* *}$ & $.725 * *$ & $.361^{* *}$ & & & \\
\hline Assertion & -.131 & $.241^{*}$ & $.450 * *$ & $.506^{* *}$ & $.494^{* *}$ & $.619^{* *}$ & & \\
\hline $\begin{array}{l}\text { Affective } \\
\text { Change }\end{array}$ & -.007 & $.343 * *$ & .166 & -.056 & -.018 & -.027 & .115 & \\
\hline $\begin{array}{l}\text { Tension } \\
\text { Reduction }\end{array}$ & .010 & .052 & $.203 *$ & $.289 * *$ & $.414^{*}$ & .169 & $.208^{*}$ & .028 \\
\hline
\end{tabular}

Note: ${ }^{*} p<.05 .{ }^{*} p<.01$ 
Drinking motives and alexithymia 16

This is an Accepted Manuscript version of the following article:

Lyvers, M., Simons, O., Hayes, A., \& Thorberg, F. A. (2014). Drinking motives, alcohol expectancies and alexithymia in young adult social drinkers. Journal of Substance Use, 19(1-2), 44-47. https://doi.org/10.3109/14659891.2012.734538.

It is deposited under the terms of the Creative Commons Attribution-NonCommercial-NoDerivatives License, which permits non-commercial re-use, distribution, and reproduction in any medium, provided the original work is properly cited, and is not altered, transformed, or built upon in any way. 